\title{
Myositis autoantibodies and clinical phenotypes
}

\author{
Anna Ghirardello $\cdot$ Elisabetta Borella $\cdot$ \\ Marianna Beggio • Franco Franceschini • \\ Micaela Fredi · Andrea Doria
}

Received: 16 June 2014 / Accepted: 1 July 2014/Published online: 23 August 2014

(C) Springer International Publishing Switzerland 2014

\begin{abstract}
Autoantibodies are powerful diagnostic tools in idiopathic inflammatory myopathies, especially for confirming the diagnosis and contributing to the definition of disease subsets. They are present in over $80 \%$ of patients with immuno-mediated myositis and directed towards ubiquitously expressed intracellular complexes. Most of these autoantibodies are reported also in other autoimmune diseases, while some are considered myositis-specific. Myositis autoantibodies are traditionally categorized in two groups, based on their diagnostic accuracy: myositis-specific antibodies (MSA) and myositis-associated antibodies (MAA), the latter mostly occurring in myositis-overlap syndromes. Besides the so-called traditional MSA, including anti-synthetases, anti-SRP and anti-Mi-2 antibodies, additional newly conceived immune targets have been recently identified, mostly in patients with severe forms of dermatomyositis or necrotizing myopathy. They mainly encompass enzymatic proteins essentially involved in the regulation of gene transcription or post-translational modifications, i.e., TIF1- $\gamma$, NXP-2, MDA5, SAE and HMGCR. Among the MAA, anti-PM/Scl and anti-Ku characterize an overlap polydermatomyositis/systemic
\end{abstract}

A. Ghirardello · E. Borella · M. Beggio · A. Doria $(\bowtie)$

Division of Rheumatology, Department of Medicine, University of Padova, Via Giustiniani, 2, 35128 Padua, Italy

e-mail: adoria@unipd.it

F. Franceschini - M. Fredi

Rheumatology and Clinical Immunology Unit,

AO Spedali Civili di Brescia, Brescia, Italy

M. Fredi

Department of Clinical and Experimental Sciences,

University of Brescia, Brescia, Italy sclerosis syndrome with severe interstitial lung involvement.

Keywords Autoimmune myositis - Autoantibodies · Myositis-specific antibodies · Overlap syndrome

\section{Introduction}

Serum autoantibodies towards ubiquitary intracellular constituents are found in more than $80 \%$ of patients with polymyositis (PM) or dermatomyositis (DM). Some autoantibody specificities are shared with other connective tissue diseases (CTD), others are almost exclusive of patients with autoimmune myositis. As well as in other CTD, the identification of autoantibodies in serum has become an important milestone in the diagnosis of idiopathic inflammatory myopathies (IIM).

The clinically important autoantibodies are classically categorized in two groups based on their diagnostic accuracy: the myositis-specific antibodies (MSA) and the myositis-associated antibodies (MAA) (Table 1). By definition, MSA are specific of autoimmune myositis, diagnostic specificity exceeding $90 \%$, and target cytoplasmic or nuclear ribonucleoproteins involved in key processes of cell biology such as gene transcription, protein synthesis and translocation, and innate antiviral immune response (Table 2). They are mutually exclusive and closely associated with distinct disease subsets differing in clinical involvement and prognosis [1]. On the other hand MAA, even though present in up to $50 \%$ of myositis patients, are not disease-specific, frequently associated with MSA, and mostly found in myositisoverlap syndrome, primarily myositis-systemic sclerosis (PDM/SSc) [2]. 
Table 1 Autoantibodies in poly/dermatomyositis

\section{Myositis-Specific Antibodies Myositis-Associated Antibodies}

- Anti-Ro

- Anti-PM/Scl

- Anti-Ku

- Anti-SRP

- Anti-U1RNP
- Anti-TIF1- $\gamma$

- Anti-NXP-2

- Anti-MDA5

- Anti-SAE

- Anti-HMGCR
Novel

autoantibodies
Myositis-specific autoantigens are largely heterogeneous in functional and biochemical characteristics: the classic ones are the aminoacyl-tRNA synthetases (ARS), the Mi-2 helicase/histone deacetylase protein complex, and the signal recognition particle (SRP) [3-5]. During the last decade, new putative myositis autoantigens have been identified, including TIF1- $\gamma$, NXP-2, MDA5, SAE, and HMGCR [6-11]. The diagnostic accuracy of newly conceived autoantibodies is far from being ascertained; however, they are promising and in the future they could expand the MSA spectrum improving our ability in diagnosis and classification of myositis.

\section{Myositis-specific antibodies (MSA) and disease subsets}

\section{Anti-ARS antibodies}

ARS are cytoplasmic enzymes that catalyze the binding of each amino acid to its cognate tRNA during protein synthesis. As immunological targets, eight tRNA synthetases have been identified so far: histidyl (Jo-1), threonyl (PL-7), alanyl (PL-12), glycyl (EJ), isoleucyl (PL-12), asparaginyl (KS), tyrosyl (Ha), and phenylalanyl (Zo) synthetases. Antibodies to ARS overall occur in $25-35 \%$ of IIM patients [1]. Anti-Jo-1 is the most common, found in $20-30 \%$ of patients with PM and $60-70 \%$ of myositis patients with interstitial lung disease (ILD). Anti-PL-7, PL12 , are found in less than $5 \%$, and anti-KS, -OJ, -EJ, -Zo, -Ha, in less than $2 \%$ of PM or DM. Taken together, antiARS are associated with a clinical syndrome featured by myositis and high occurrence of ILD, arthritis, Raynaud's phenomenon and "mechanic's hands", named anti-ARS syndrome. Lungs and joints are the major organs involved, and disease prognosis is strictly related to pulmonary involvement. Even if anti-ARS syndrome was described as a clinical variant of PM or DM, it is now considered a true overlap syndrome [12].

Anti-Mi-2 antibody

Mi-2/nucleosome remodeling and histone-deacetylase complex participates in the regulation of gene expression via chromatin modifications. Anti-Mi-2 antibodies are found in 10-30\% of patients with IIM, especially DM, being associated with specific skin involvement, like Gottron's sign or papules and heliotrope rash, lung sparing and good response to steroids [4]. Moreover, anti-Mi-2 antibody seems to be associated with a lower risk of paraneoplastic myositis, thus being considered a good prognostic factor [4, 13].

\section{Anti-SRP antibody}

SRP is a highly conserved cytoplasmic multimeric ribonucleoprotein, consisting of six polypeptides complexed with one 7SL RNA, that is involved in secretory protein recognition and translocation across the rough endoplasmic reticulum. Anti-SRP antibodies are specific for IIM, being found in $4-8 \%$ of PM patients $[1,5]$. They are strictly associated with the anti-SRP syndrome, a severe necrotizing myopathy, histologically characterized by abundant myofiber necrosis and regeneration, with scarce inflammation. Rapidly progressive muscle weakness and poor 
Table 2 Myositis-specific antibodies: target antigens and clinical associations in adult myositis patients

\begin{tabular}{|c|c|c|c|}
\hline Autoantibody & Immune target & $\begin{array}{l}\text { Function of } \\
\text { autoantigen }\end{array}$ & $\begin{array}{l}\text { Clinical } \\
\text { associations }\end{array}$ \\
\hline $\begin{array}{l}\text { Anti-ARS } \\
\text { (Jo-1, PL-7, } \\
\text { PL-12, EJ, } \\
\text { OJ, KS, Ha, } \\
\text { Zo) }\end{array}$ & $\begin{array}{l}\text { tRNA } \\
\text { synthetases }\end{array}$ & $\begin{array}{l}\text { Aminoacylation } \\
\text { of tRNAs }\end{array}$ & $\begin{array}{l}\text { PM } \\
\text { Anti- } \\
\text { synthetase } \\
\text { syndrome }\end{array}$ \\
\hline Anti-Mi-2 & NuRD subunit & $\begin{array}{l}\text { Gene } \\
\text { transcription } \\
\text { Nucleosome } \\
\text { remodeling }\end{array}$ & $\begin{array}{l}\text { "Classic } \\
\text { DM" } \\
\text { Mild disease }\end{array}$ \\
\hline Anti-TIF1- $\gamma$ & $\begin{array}{l}\text { Transcriptional } \\
\text { intermediary } \\
\text { factor } 1 \gamma\end{array}$ & $\begin{array}{l}\text { Ubiquitination } \\
\text { Gene } \\
\text { transcription }\end{array}$ & $\begin{array}{l}\text { Severe DM } \\
\text { Cancer- } \\
\text { associated } \\
\text { DM }\end{array}$ \\
\hline Anti-NXP-2 & $\begin{array}{l}\text { Nuclear matrix } \\
\text { protein } 2\end{array}$ & $\begin{array}{l}\text { Gene } \\
\text { transcription }\end{array}$ & $\begin{array}{l}\text { Severe DM } \\
\text { Cancer- } \\
\text { associated } \\
\text { DM }\end{array}$ \\
\hline Anti-MDA5 & $\begin{array}{l}\text { Melanoma } \\
\text { differentiation- } \\
\text { associated } \\
\text { protein } 5\end{array}$ & $\begin{array}{l}\text { Innate antiviral } \\
\text { response }\end{array}$ & $\begin{array}{l}\text { Amyopathic } \\
\text { DM } \\
\text { ILD } \\
\text { Poor } \\
\text { prognosis }\end{array}$ \\
\hline Anti-SAE & $\begin{array}{l}\text { SUMO-1 } \\
\text { activating } \\
\text { enzyme }\end{array}$ & $\begin{array}{l}\text { Protein } \\
\text { sumoylation } \\
\text { Gene } \\
\text { transcription }\end{array}$ & $\begin{array}{l}\text { DM } \\
\text { Initially } \\
\text { amyopathic } \\
\text { DM }\end{array}$ \\
\hline Anti-SRP & $\begin{array}{l}\text { Signal } \\
\text { recognition } \\
\text { particle }\end{array}$ & $\begin{array}{l}\text { Protein } \\
\text { translocation } \\
\text { across the ER }\end{array}$ & $\begin{array}{r}\text { Necrotizing } \\
\text { myopathy }\end{array}$ \\
\hline $\begin{array}{l}\text { Anti- } \\
\text { HMGCR }\end{array}$ & $\begin{array}{l}\text { 3-Hydroxy-3- } \\
\text { methylglutaryl- } \\
\text { CoA reductase }\end{array}$ & $\begin{array}{l}\text { Cholesterol } \\
\text { biosynthesis }\end{array}$ & $\begin{array}{l}\text { Necrotizing } \\
\text { myopathy } \\
\text { Prior statin } \\
\text { use }\end{array}$ \\
\hline
\end{tabular}

tRNAs transfer RNAs, $P M$ polymyositis, $N u R D$ nucleosome remodeling-histone deacetylase, $D M$ dermatomyositis, $I L D$ interstitial lung disease, SUMO-1 small ubiquitin-like modifier 1, ER rough endoplasmic reticulum

response to standard treatment are the characteristic prognostic features [5].

\section{Anti-TIF1- $\gamma$ antibody}

This novel putative MSA, firstly described few years ago, is exclusively found in 20-30 \% of adult as well as juvenile DM. It targets nuclear transcription factors belonging to the human transcriptional intermediatory factor (TIF-1) family, primarily TIF1- $\gamma$. Anti-TIF1- $\gamma$ antibody is significantly associated with aggressive skin lesions both in adult and juvenile DM, whereas the established association with paraneoplastic DM is largely confined to adult patients, especially the older ones ( $>50$ years). Intriguingly, TIF-1 proteins are over-expressed in solid tumors, i.e., adenocarcinoma, and implicated in the regulation of p53 oncogene suppressor. The diagnostic value of anti-TIF1- $\gamma$ antibody testing has been recently assessed: high antibody levels anti-TIF1- $\gamma$ increase the risk of cancer-associated DM in adults, whereas negative antibody prompts to exclude concurrent malignancy, due to its very high negative predictive value [6].

\section{Anti-NXP-2 antibody}

This autoantibody targets a $140-\mathrm{kDa}$ nuclear protein, named nuclear matrix protein 2 (NXP2), which plays a role in the regulation of p53-induced apoptosis after oncogenic stimuli. To date, anti-NXP-2 antibodies have been reported in about $25 \%$ of juvenile or adult DM, and rarely in PM. Joung-onset DM, severe cutaneous lesions, including calcinosis, and muscle contractures are the prominent features [14]. An association with cancer has been observed in adults, especially in males. Recently, Fiorentino et al. [7] assessed the diagnostic value of anti-TIF1- $\gamma$ and anti-NXP2 antibody testing for cancer-associated DM, confirming that they overall occur in more than $50 \%$ of otherwise "antibody negative" patients, and are independently associated with cancer. Moreover, the authors provided evidence that accurate laboratory testing for such antibodies should be included in the diagnostic workup in order to identify the vast majority of patients with cancer-associated DM.

Anti-MDA5 antibody

This novel MSA has been firstly described in $20-30 \%$ of Asian populations, as specific of DM and associated with a clinical subset characterized by clinically amyopathic DM and rapidly progressive ILD [8]. IFN-induced melanoma differentiation-associated protein 5 (MDA5) is as the identified autoantigen, which regulates the innate antiviral immune response against cytoplasmic viral RNA. The clinical relevance of anti-MDA5 antibodies seems to be confirmed also in Caucasian IIM cohorts [9], but it is still a matter of research.

Anti-SAE antibody

Strictly related to a specific HLA haplotype, anti-small ubiquitin-like modifier activating enzyme (SAE) antibodies are found in $8 \%$ of adult DM patients, presenting with severe skin disease, dysphagia and systemic features; prognosis is favorable [10]. They target the SUMO-1 activating enzyme heterodimer, a small nuclear protein structurally similar to ubiquitin, which leads to a post- 

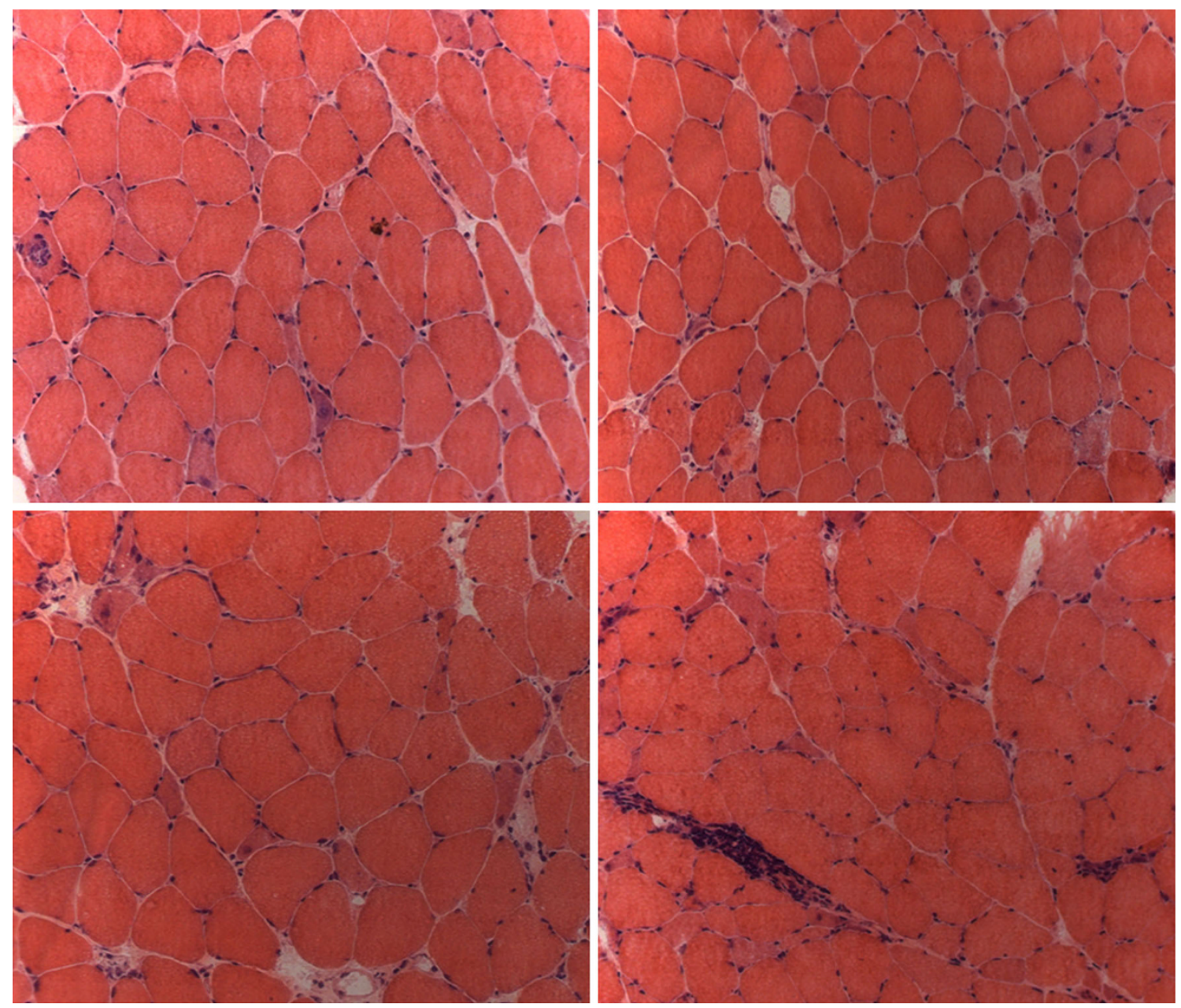

Fig. 1 Muscle biopsy from a patient with polymyositis and antiHMGCR autoantibodies (hematoxylin-eosin stain, original magnification $\times 20$ ). The biopsy shows scattered necrotic fibers, some of

which invaded by mononuclear cells, basophilic regenerating fibers and an inflammatory infiltrate in the perimysium. (Courtesy of Dr. Vattemi G.)

translational enzymatic aggregation/conjugation of proteins, called "protein sumoylation".

\section{Anti-HMGCR antibody}

A putative MSA was discovered in 3-8 \% of adult patients with IIM, as directed against 3-hydroxy-3-methylglutarylcoenzyme A reductase (HMGCR), a key enzyme of the cholesterol biosynthesis, specifically inhibited by statins. Anti-HMGCR antibody has been proposed as a serological marker of immune-mediated necrotizing myopathy, often but not exclusively induced by statin exposure [11]. Clinical phenotype of anti-HMGCR-positive patients resembled that observed in other forms of IIM: proximal muscle weakness, markedly elevated creatine kinase levels, myopathic features on electromyography, and response to immunosuppressive therapy. Myofiber necrosis and degeneration is the characteristic histopathologic feature,

occasionally accompanied by aspecific inflammatory cell infiltration (Fig. 1).

\section{Myositis-associated antibodies (MAA) and overlap syndromes}

Major MAA include anti-Ro/SSA, anti-PM/Scl, and anti$\mathrm{Ku}$ and anti-U1RNP antibodies. MAA are often found when PM or DM occurs as a component of another CTD, and thus contributing to the clinical spectrum of an overlap syndrome, though MAA may also be present in patients without overlap CTD. The overlap syndrome between PM/DM and systemic sclerosis (PDM/SSc), also called scleromyositis, is the most common and according to a recent review of the literature it appears to represent more than $44 \%$ of all scleroderma overlap syndromes [2]. 
Anti-Ro/SSA antibody, mostly directed against the Ro52 subunit, is the most prevalent MAA in myositis, found in more than $30 \%$ of patients, frequently concomitant with anti-ARS antibodies or other MAA [15]. It has been recently reported that anti-Ro52 antibody could have a prognostic value in anti-Jo-1 positive patients, being associated with a higher risk of severe ILD, myositis, joint involvement, and cancer compared with anti-Jo1-positive patients without anti-Ro52 antibodies [16]. In addition, anti-Ro/SSA and/or anti-La/SSB antibodies are frequently encountered in PDM/Sjögren (SS) overlap syndrome, which is reported in $5.3 \%$ of PDM patients, while myositis in primary SS is variably reported in 1-14\% of cases [17].

Anti-PM/Scl and anti-Ku antibodies can be somehow considered markers of PDM/SSc. Antibodies to PM/Scl are generally found in PM, DM or SSc patients, with the highest occurrence in PDM/SSc. A meta-analysis of the studies on anti-PM/Scl antibodies showed that anti-PM/Scl was found in $31 \%$ of patients with PDM/SSc, compared to $8 \%$ of PM, $11 \%$ of DM and $2 \%$ of SSc. On the other hand, PDM/SSc is diagnosed in $59 \%$ of patients with anti$\mathrm{PM} / \mathrm{Scl}$ [18]. Apart from myositis, the most frequent clinical manifestations reported in anti-PM/Scl-positive PDM/ SSc patients consist of Raynaud's phenomenon, ILD, arthritis and skin involvement, including "mechanic's hands". While muscle involvement is often subclinical in $\mathrm{PDM} / \mathrm{SSc}$ with PM/Scl antibodies, ILD has the same clinical and pathological features and severity observed in patients with anti-ARS syndrome [19].

Even though detected in a wide spectrum of CTD, anti$\mathrm{Ku}$ antibody should be considered as a marker of PDM/ $\mathrm{SSc}$, either because it was first described in patients with $\mathrm{PDM} / \mathrm{SSc}$, which was reported in about $25 \%$ of anti-Ku positive patients, or because the clinical manifestations are the same as in anti-ARS and anti-PM/Scl overlap syndrome [20]. Moreover, while the inflammatory myopathy is usually mild and responds to corticosteroid treatment, lung involvement is severe and refractory to corticosteroids, as in both anti-ARS and anti-PM-Scl overlap syndrome [21]. Anti-PM/Scl and anti-Ku positive PDM/SSc are preferentially associated with the limited cutaneous variant of SSc $[20,22]$, presenting less digital ulcers and much more myositis, arthritis and ILD, compared with anti-centromere antibody positive limited SSc [20]. Notably, both anti-PM/ Scl antibody and the associated PDM/SSc recognize an immunogenetic background characterized by the haplotype HLA-DQA $1 * 0501$, DQB1*02, DRB1*0301 [22].

Anti-U1RNP antibodies are significantly more frequent in PDM/systemic lupus erythematosus (SLE) overlap syndrome than in SLE and they are associated with anti-Jo1 antibodies in such condition. In addition to myositis, erosive arthritis, alopecia, ILD and oral ulcers are prevalent findings in patients with PDM/SLE overlap syndrome.
Conversely, renal disease is very rare. Nevertheless, patients with SLE and myositis were likely to die at a young age. The onset of myositis can antedate, be concomitant or follow the appearance of SLE manifestations. $\mathrm{DM}$ is more common than PM [23].

By reviewing a cohort of 110 outpatients with PDM attending Brescia Rheumatology and Clinical Immunology Unit from 1990 to 2013, an overlap syndrome with CTD was diagnosed in 23 patients (21\%): 14 with SSc $(61 \%)$, 3 with SLE (13\%), 4 with SS (17\%) and 2 with rheumatoid arthritis (9\%). A similar prevalence of overlap syndrome in PDM was also reported in recent studies [17], where myositis was classified according to the commonly used Bohan and Peter's criteria. Interestingly, a modified classification of these criteria has been proposed [15], taking into account the presence of extra muscular clinical manifestations and/or autoantibodies other than anti-Mi-2, considered highly specific for pure DM. With such an approach, the majority of inflammatory myositis should be diagnosed as overlap myositis syndrome. Furthermore, combining autoantibody testing to the original classification allows us to better understand the value of autoantibodies in the diagnosis and prognosis definition, and in predicting the response to corticosteroid treatment.

\section{Laboratory detection of myositis autoantibodies}

Testing for MSA and MAA is a useful aid for the diagnosis and subset definition of autoimmune myositis. However, many target antigens are poorly expressed in cell/tissue extracts or highly sensitive to degradation/denaturation, thus limiting the standardization of methods for diagnostic purpose. Therefore, most MSA are still detected through different time-consuming non-standardized techniques. Recently, a single multianalytic line blot assay has been validated as screening test for MSA/MAA in clinical practice [24]. On the basis of our experience, we suggest to include line blot as an initial screen in suspected IIM. Patients seronegative by line blot testing should be evaluated by in-house speculative testing.

At present, new antibody specificities are accurately detected by immunoprecipitation of radiolabeled proteins or RNA molecules; however, commercially available ELISA or immunoblot assays will be available in the near future.

\section{Autoantibodies as clues in the pathogenesis of myositis}

The aforementioned association of MSA with distinct clinical phenotypes and disease prognosis, and the correlation between serum antibody levels and disease activity, 
provide clues on the pathogenetic role of autoantibodies in $\mathrm{PM} / \mathrm{DM}$. Evidence is increasing that myositis autoantigens are able to drive a B cell antigen-specific immune response in muscles. Intriguingly, after the pioneeristic study by Casciola-Rosen et al. [25], several groups confirmed the aberrant expression of Jo-1, Mi-2, HMGCR and other myositis antigens in regenerating fibers from PM and DM muscle biopsies compared with controls. In addition, overexpression of both classic and novel myositis antigens has been demonstrated in other target organs, such as Jo-1 in the lung, Mi-2 in the epidermal basal membrane, and also TIF1- $\gamma$ and NXP-2 in adenocarcinoma tissues. In target tissues, myositis antigens show strong adjuvant and chemoattractant properties, acting per se as proinflammatory and immunostimulating agents, either in the muscle or far from it, i.e., in the lung, skin or tumors. Thus, regenerating muscle fibers and tumor cells seem to share similar immunostimulating phenotypes, suggesting a pathogenetic link between cancer and autoimmunity in myositis [26]. Finally, association of most myositis autoantigens with nucleic acids makes them likely to stimulate the IFN type I secretion pathways which in turn can increase antigen availability and propagation of the immune response [27].

\section{Conclusions}

MSA are disease serological markers, mutually exclusive and closely associated with distinct disease subsets. Moreover, they seem to be directly involved in the induction and perpetuation of muscle damage. Therefore, their detection in the early phase of the disease might be helpful in the prediction of clinical course and disease prognosis.

\section{Conflict of interest None.}

Human and animal rights All procedures performed in studies involving human participants were in accordance with the ethical standards of the institutional and/or national research committee and with the 1964 Helsinki declaration and its later amendments or comparable ethical standards.

Informed consent The study was approved by the Local Ethics Committee and informed consent was obtained from all patients, in compliance with the Helsinki Declaration.

\section{References}

1. Ghirardello A, Bassi N, Palma L et al (2013) Autoantibodies in polymyositis and dermatomyositis. Curr Rheumatol Rep 15:335. doi:10.1007/s11926-013-0335-1

2. Iaccarino L, Gatto M, Bettio S et al (2012) Overlap connective tissue disease syndromes. Autoimmun Rev 3:363-373

3. Zampieri S, Ghirardello A, Iaccarino L, Tarricone E, Gambari PF, Doria A (2005) Anti-Jo-1 antibodies. Autoimmunity 38:73-78
4. Ghirardello A, Zampieri S, Iaccarino L et al (2005) Anti-Mi-2 autoantibodies. Autoimmunity 38:79-83

5. Hengstman GJ, ter Laak HJ, Vree Egberts WT et al (2006) Antisignal recognition particle autoantibodies: marker of a necrotising myopathy. Ann Rheum Dis 65:1635-1638

6. Trallero-Araguas E, Rodrigo-Pendas JA, Selva-O'Challagan A et al (2012) Usefulness of anti-p155 autoantibody for diagnosing cancer-associated dermatomyositis. A systematic review and meta-analysis. Arthritis Rheum 64:523-532

7. Fiorentino DF, Chung LS, Christopher-Stine L et al (2013) Most patients with cancer-associated dermatomyositis have antibodies to nuclear matrix protein NXP-2 or transcription intermediary factor $1 \gamma$. Arthritis Rheum 65:2954-2962. doi:10.1002/art.38093

8. Cao H, Pan M, Kang Y et al (2012) Clinical manifestations of dermatomyositis and clinically amyopathic dermatomyositis patients with positive expression of anti-melanoma differentiation-associated gene 5 antibody. Arthritis Care Res 64:1602-1610

9. Hall JC, Casciola-Rosen L, Samedy LA et al (2013) Anti-melanoma differentiation-associated protein 5-associated dermatomyositis: expanding the clinical spectrum. Arthritis Care Res 65:1307-1315. doi:10.1002/acr.21992

10. Tarricone E, Ghirardello A, Rampudda M, Bassi N, Punzi L, Doria A (2012) Anti-SAE antibodies in autoimmune myositis: identification by unlabelled protein immunoprecipitation in an Italian patient cohort. J Immunol Methods 384:128-134

11. Mohassel P, Mammen AL (2013) Statin-associated autoimmune myopathy and anti-HMGCR autoantibodies. Muscle Nerve 48:477-483. doi:10.1002/mus.23854

12. Mahler M, Miller FW, Fritzler MJ (2014) Idiopathic inflammatory myopathies and the anti-synthetase syndrome: a comprehensive review. Autoimmun Rev 13:367-371. doi:10.1016/j. autrev.2014.01.022

13. Iaccarino L, Ghirardello A, Bettio S et al (2014) The clinical features, diagnosis and classification of dermatomyositis. J Autoimmun 48-49:122-127. doi:10.1016/j.jaut.2013.11.005

14. Ceribelli A, Fredi M, Taraborelli M et al (2012) Anti-MJ/NXP-2 autoantibody specificity in a cohort of adult Italian patients with polymyositis/dermatomyositis. Arthritis Res Ther 14:R97. doi:10. 1186/ar3822

15. Troyanov Y, Targoff IN, Tremblay JL, Goulet JR, Raymond Y, Senécal JL (2005) Novel classification of idiopathic inflammatory myopathies based on overlap syndrome features and autoantibodies: analysis of 100 French Canadian patients. Medicine (Baltimore). 84:231-249

16. Marie I, Hatron PY, Dominique S et al (2012) Short-term and long-term outcome of anti-Jo1-positive patients with anti-Ro52 antibody. Semin Arthritis Rheum 41:890-899

17. Váncsa A, Gergely L, Ponyi A et al (2010) Myositis-specific and myositis-associated antibodies in overlap myositis in comparison to primary dermatopolymyositis: Relevance for clinical classification: retrospective study of 169 patients. Jt Bone Spine 77:125-130

18. Mahler M, Raijmakers R (2007) Novel aspects of antibodies to the PM/Scl complex: clinical, genetics and diagnostic insights. Autoimmun Rev 6:432-437

19. Lega JC, Cottin V, Fabien N, Thivolet-Béjui F, Cordier JF (2010) Interstitial lung disease associated with anti-PM/Scl or antiaminoacyl-tRNA synthetase autoantibodies: a similar condition? J Rheumatol 37:1000-1009

20. Cavazzana I, Fredi M, Taraborelli M, Quinzanini M, Tincani A, Franceschini F (2013) A subset of systemic sclerosis but not of systemic lupus erythematosus is defined by isolated anti-Ku autoantibodies. Clin Exp Rheumatol 31:118-121

21. Rigolet A, Musset L, Dubourg O et al (2012) Inflammatory myopathies with anti-Ku antibodies: a prognosis dependent on associated lung disease. Medicine (Baltimore) 91:95-102 
22. Ho KT, Reveille JD (2003) The clinical significance of autoantibodies in scleroderma. Arthritis Res Ther 5:80-93

23. Dayal NA, Isenberg DA (2002) SLE/myositis overlap: are the manifestations of SLE different in overlap disease? Lupus 11:293-298

24. Ghirardello A, Rampudda M, Ekholm L et al (2010) Diagnostic performance and validation of autoantibody testing in myositis by a commercial line blot assay. Rheumatology (Oxford) 49:2370-2374
25. Casciola-Rosen L, Nagaraij K, Plots P et al (2005) Enhanced autoantigen expression in regenerating muscle cells in idiopathic inflammatory myopathy. J Exp Med 201:591-601

26. Zampieri S, Doria A, Adami N et al (2010) Subclinical myopathy in patients affected with early stage colorectal cancer at disease onset: evidence from skeletal muscle biopsies. Neurol Res 32:20-25

27. Lundberg IE, Helmers SB (2010) The type I interferon system in idiopathic inflammatory myopathies. Autoimmunity 43:239-243 